\title{
Functional mapping of the cardiorespiratory effects of dorsal and median raphe nuclei in the rat
}

\section{R.M. Alvarenga ${ }^{1}$, \\ J.G.P. Pires ${ }^{1}$ and \\ H.A. Futuro $\mathrm{Neto}^{1,2}$}

\author{
1Programa de Pós-Graduação em Ciências Fisiológicas, Centro Biomédico, \\ Universidade Federal do Espírito Santo, Vitória, ES, Brasil \\ ${ }^{2}$ Escola Superior de Ciências da Santa Casa de Misericórdia, Vitória, ES, Brasil
}

\section{Correspondence \\ H.A. Futuro Neto \\ CBM/UFES \\ Av. Marechal Campos, 1468 \\ 29042-755 Vitória, ES \\ Brasil \\ Fax: +55-27-3335-7330 \\ E-mail: futuront@npd.ufes.br \\ Research supported by CNPq and FINEP.}

Received June 18, 2004 Accepted May 10, 2005

\begin{abstract}
The dorsal (DRN) and median (MRN) raphe nuclei are important sources of serotonergic innervation to the forebrain, projecting to sites involved in cardiovascular regulation. These nuclei have been mapped using electrical stimulation, which has the limitation of stimulating fibers of passage. The present study maps these areas with chemical stimulation, investigating their influence on cardiorespiratory parameters. Urethane-anesthetized $(1.2 \mathrm{~g} / \mathrm{kg}, i v)$ male Wistar rats (280-300 g) were instrumented for pulsatile and mean blood pressure (MBP), heart rate, renal nerve activity, and respiratory frequency recordings. Microinjections of L-glutamate ( $0.18 \mathrm{M}, 50-100 \mathrm{nl}$ with $1 \%$ Pontamine Sky Blue) were performed within the DRN or the MRN with glass micropipettes. At the end of the experiments the sites of microinjection were identified. The majority of sites within the MRN (86.1\%) and DRN (85.4\%) evoked pressor responses when stimulated (DRN: $\Delta \mathrm{MBP}=+14.7 \pm 1.2 ; \mathrm{MRN}: \Delta \mathrm{MBP}=+13.6 \pm 1.3 \mathrm{mmHg}$ ). The changes in renal nerve activity and respiratory rate caused by Lglutamate were $+45 \pm 11$ and $+42 \pm 9 \%$ (DRN; $\mathrm{P}<0.05 \%$ ), $+40 \pm 10$ and $+29 \pm 7 \%$ (MRN, $\mathrm{P}<0.05$ ), respectively. No significant changes were observed in saline-microinjected animals. This study shows that: a) the blood pressure increases previously observed by electrical stimulation within the raphe are due to activation of local neurons, b) this pressor effect is due to sympathoexcitation because the stimulation increased renal sympathetic activity but did not produce tachycardia, and c) the stimulation of cell bodies in these nuclei also increases the respiratory rate.
\end{abstract}

Key words

- Dorsal raphe nucleus

- Median raphe nucleus

- L-glutamate

- Blood pressure

- Respiration

- Sympathetic nerve activity

\section{Introduction}

The dorsal (DRN) and median (MRN) raphe nuclei provide almost all the serotonergic innervation to the forebrain $(1,2)$. By contrast, caudal serotonin (5-HT) cell groups in the lower brainstem (raphe pallidus, magnus and obscurus) provide descending projections to the spinal cord (3-8). DRN and MRN projections are organized in such a way that some forebrain areas receive mixed DRN/MRN projections while others have selective DRN or MRN inputs (9-14). DRN fibers project mainly laterally to areas such as the amygdala, lateral preoptic area, substantia innominata, nucleus accumbens, stria- 
tum, and substantia nigra pars compacta $(13,15)$. In contrast, MRN fibers make connections with DRN neurons and also ascend within the medial forebrain bundle, projecting to structures such as the perifornical hypothalamus, medial septum and interpeduncular nucleus. In this respect, the MRN represents a midline/paramidline system of projections (16). Even though these connections are supposed to be serotonergic, nonserotonergic ascending projections from the raphe cannot be ruled out $(9,13,16)$.

Raphe neurons innervating the forebrain have a critical and diverse role in regulating autonomic functions (17-19) as well as mood, sleep, learning, and memory (20). Tracing studies revealed the existence of a reciprocal pathway between the DRN and MRN, which is at least partially serotonergic (16,21-23). Electrical or chemical stimulation of either nucleus elicits similar cardiovascular and behavioral responses (17-19,24). For instance, electrical stimulation of DRN or MRN elicits pressor responses in the anesthetized rat, that seem to require the participation of the rostral ventrolateral medulla (RVLM), considered a major component of the formerly called "vasomotor center" of the brainstem $(25,26)$. If the connections between DRN or MRN and RVLM are mainly direct $(25,26)$ or via suprasegmental structures (e.g., hypothalamus) is not known.

Several studies have attempted to clarify the role of the raphe nuclei in cardiovascular control $(16,17,24)$. These studies employed electrical stimulation and showed that stimulation of DRN and MRN induces mainly pressor responses in the rat, and that these responses are mediated by 5 -HT. However, these conclusions have an intrinsic problem, due to the technique employed which stimulates not only cell bodies, but also fibers of passage. In contrast, the few studies employing chemical stimulation of the DRN in the cat (19) and rat (27) elicited pressor responses. However, these studies were restricted to the DRN and did not analyze respiratory effects. Therefore, the present study was designed to specifically evaluate the effects of activation of neurons both in the DRN and MRN with L-glutamate (LGlu) on cardiovascular and respiratory regulation in the rat. Part of these results were published in abstract form (28).

\section{Material and Methods}

Experiments were performed on 65 anesthetized, spontaneously breathing, male Wistar rats (280-300 g). Anesthesia was produced with urethane $(1.2 \mathrm{~g} / \mathrm{kg}, i v)$ after induction with ether. Supplementary doses of anesthetic $(0.2 \mathrm{~g} / \mathrm{kg}, i v)$ were administered when necessary, as indicated by the pupil size, paw pinch reflexes and unstable heart rate (HR) and/or blood pressure (BP). The left femoral artery was cannulated with a polyethylene catheter filled with heparinized saline (40 units $/ \mathrm{ml}$ ) for BP measurements. The arterial catheter was connected to a strain gauge transducer (Viggo-Spectramed, P23XL, Oxnard, CA, USA) and the pulsatile BP was recorded on a polygraph (Gould RS3400, pressure processor Gould 20-4615, Valley View, OH, USA). HR was derived from the arterial pressure pulse wave using a rate-meter (Gould 13-64615). The left femoral vein was cannulated for drug administration. A tracheotomy was performed on all animals and respiration was recorded with a pneumotachograph (Fleisch model 0000, Richmond, VA, USA) connected to a low-pressure transducer (Validyne DP45, Northridge, CA, USA) and a carrier amplifier (Gould 20-4615).

The left renal sympathetic nerve was dissected retroperitoneally. Fine silver wire electrodes were carefully applied; the nerve and electrode were covered with dental resin (President ${ }^{\circledR}$, Coltene, Mahwah, NJ, USA) to avoid movement and to isolate the nerve from surrounding fluid or air. Electrophysiological signals were amplified (pre-amplifier NL 100AK, AC amplifier NL 104, fil- 
ters NL 126, Digitimer, Welwyn Garden, Hertfordshire, England) and connected to an audio amplifier (NL 120) and to an oscilloscope (Tektronix 2205, Portland, OR, USA). Renal nerve activity was integrated with a Spike Processor D130 (Digitimer). All data were digitalized (Biopac MP100, Santa Barbara, CA, USA) and stored on a PC hard disk.

The head of the animal was fixed on a stereotaxic frame (Stoelting, Wood Dale, IL, USA). An occipital craniotomy was performed so as to expose the brainstem, in order to allow the insertion of the micropipettes. Rectal temperature was maintained between $36-37^{\circ} \mathrm{C}$ with a homeothermic blanket (Harvard, South Natick, MA, USA).

L-Glu (0.18 M, with 1\% Pontamine Sky Blue dye) or saline (plus 1\% Pontamine Sky Blue dye) was microinjected (50-100 nl) with a micropipette (internal diameter 1.17 $\mathrm{mm}$ and tip size 25-50 $\mu \mathrm{m}$; Narishige PW6 Puller, Tokyo, Japan) positioned with a hydraulic micromanipulator (Narishige MO 10). The microinjections at sites within the DRN or MRN were made with a pressure pulse and the injection volume was controlled with the eye grid of a Zeiss microscope. Only one microinjection was made in each nucleus, so that for a given experiment a maximum of two microinjections were made (L-Glu, $\mathrm{N}=41$; saline, $\mathrm{N}=5$ animals). A 30-min interval was allowed to elapse between injections. For the access to the DRN or MRN, the coordinates of the Paxinos and Watson (29) atlas were used (coordinates in relation to the interaural line; DRN AP 1.7 to $1.0 \mathrm{~mm}$, lateral 0.0 to $0.2 \mathrm{~mm}$, ventral -6.2 to $-6.0 \mathrm{~mm}$; MRN AP 1.7 to 1.0 $\mathrm{mm}$, lateral 0.0 to $0.2 \mathrm{~mm}$, ventral -8.2 to $-8.50 \mathrm{~mm}$ ). In separate experiments, a stainless steel electrode was positioned at the same target point for electrical stimulation (isolated cathodal square wave pulses for 10 $\mathrm{s}$ at $100 \mathrm{~Hz}, 40-100 \mu \mathrm{A}$ and 1-ms pulse duration). This was done to compare the effects of chemical stimulation (L-Glu) with those of electrical stimulation within the same nucleus.

At the end of the recording period the position of the stainless steel electrode was marked by passing a DC current of $200 \mu \mathrm{A}$ for $30 \mathrm{~s}$ (stainless steel electrode anode); in this manner a small deposit of iron was made at the stimulus site. At the end of the experiment the brainstem was removed and placed in $1 \%$ potassium ferrocyanide in $10 \%$ formaldehyde saline for 7 days, so that the ferrocyanide would cause the conversion of the iron deposit to an identifiable Prussian Blue spot. The microinjection sites were marked by the Pontamine Sky Blue dye that was added to saline or the L-Glu solution. Brainstem $60-\mu \mathrm{m}$ thick frontal sections were cut with a freezing microtome (Ernst Leitz, Wetzlar, Germany) and stained with neutral red. Individual maps were drawn for each experiment.

The BP and HR responses ( $\Delta$ mean blood pressure (MBP), $\Delta \mathrm{HR}$ ) to microinjections of L-Glu or saline are reported as peak effects. Unless otherwise stated, data are reported as means \pm SEM. The paired Student $t$-test was used for statistical comparisons of the means, with the level of significance set at $\mathrm{P}<0.05$.

\section{Results}

\section{Cardiovascular and respiratory effects of L-Glu microinjected into the DRN}

The baseline MBP of the urethane-anesthetized rats was $82.6 \pm 1.6 \mathrm{mmHg}$, while the HR was $372 \pm 6.0 \mathrm{bpm}$. Microinjections of L-Glu (0.18 M, $50 \mathrm{nl})$ into the DRN (N = 41 animals) induced pressor responses $(\triangle \mathrm{MBP}=+14.7 \pm 1.2 \mathrm{mmHg})$ in $85.4 \%(35 /$ 41) of the microinjection sites, while no response or a decrease in BP was observed in $7.3 \%$ of the sites (3/41 in each case). Overall, the effect on BP was hypertension, as shown in Figure 1. Changes in HR elicited by L-Glu were minimal, and the overall effect did not differ statistically from predrug values (Figure 1). 
Figure 1. Effect of L-glutamate (L-Glu; $0.18 \mathrm{M} / 50 \mathrm{nl}$ ) microinjected into the DRN $(\mathrm{N}=41)$ and MRN $(\mathrm{N}=36)$ on mean blood pressure (MBP) and heart rate $(\mathrm{HR})$ in anesthetized rats. DRN = dorsal raphe nucleus; MRN = median raphe nucleus. Open columns = control; filled columns $=\mathrm{L}$-Glu. ${ }^{*} \mathrm{P}<0.05$ compared to pre-drug values (control; paired Student $t$-test).

Figure 2. Typical tracing showing that L-Glu $(0.18 \mathrm{M} / 50 \mathrm{nl}) \mathrm{mi}-$ croinjected into the dorsal raphe nucleus (DRN) (1.2 mm AP; -6.6 $\mathrm{mm} \mathrm{V} ; 0 \mathrm{~mm} \mathrm{~L}$ ) causes increases in blood pressure (BP), mean blood pressure (MBP), renal nerve activity (RNA), integrated RNA (IRNA), and respiratory parameters (Resp), while the effect on heart rate (HR) is negligible. The time bar corresponds to $20 \mathrm{~s}$ for all measurements except for the lower respiration tracing where it is $2 \mathrm{~s}$.
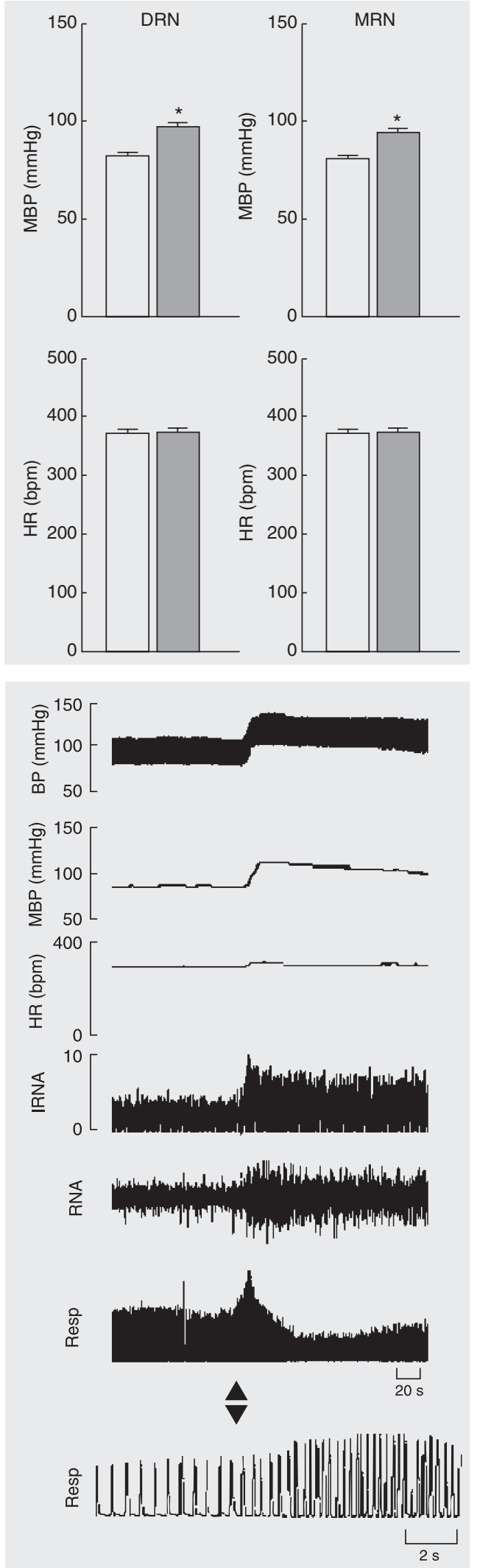

The pressor responses were accompanied by increases in renal nerve activity (RNA) and respiratory rate of variable magnitude. A typical tracing showing these effects is seen in Figure 2. The overall changes in RNA (reported as arbitrary units) and respiratory rate (baseline $=81 \pm 3.5 \mathrm{cpm}$ ) caused by L-Glu were $+45 \pm 11$ and $+42 \pm$ $9 \%$, respectively $(\mathrm{P}<0.05 \%)$. The distribution of pressor sites within the DRN was not homogenous. The rostral pole of the nucleus concentrated the majority of pressor sites, while "no response" sites were more frequent in the caudal extremity of the nucleus (Figure 3). A typical injection site into the DRN is shown in the histological plate in Figure 4.

Microinjections made outside the DRN ( $\mathrm{N}=12$ animals) did not change the cardiovascular parameters or induce a different pattern of responses (data not shown). Chemical stimulation within sites lateral to the DRN induced biphasic responses (a decrease followed by an increase in BP; $\triangle \mathrm{MBP}=-10$ to $+15 \mathrm{mmHg}, \mathrm{N}=2$ ) accompanied by an increase in respiratory rate and in RNA. In four other animals the stimulation induced an increase in $\mathrm{BP}(\mathrm{MBP}=83.8 \pm 2.3$ to 99.5 $\pm 3.1 \mathrm{mmHg}$ ) and apnea. A decrease in BP $(\mathrm{MBP}=87 \pm 3.7$ to $77.3 \pm 3.2 \mathrm{mmHg}$ ) and no change in respiratory rate was observed in two other animals. In four other animals, no change in cardiovascular parameters were induced by the stimulation (MBP $=98.4 \pm$ $2.5 \mathrm{mmHg} ; \mathrm{HR}=388.1 \pm 2.9 \mathrm{bpm}$ ).

\section{Cardiovascular and respiratory effects of electrical stimulation of the DRN}

For this group ( $\mathrm{N}=6$ animals), baseline MBP was $81.5 \pm 1.1 \mathrm{mmHg}$ and $\mathrm{HR}$ was 373 $\pm 8.2 \mathrm{bpm}$ in the anesthetized rats. Electrical stimulation $(1 \mathrm{~ms}, 100 \mathrm{~Hz}, 100 \mu \mathrm{A}$, for $10 \mathrm{~s})$ of sites within the DRN caused cardiorespiratory effects quite similar to those obtained from chemostimulation with L-Glu. The pressor response had a magnitude of $36.6 \pm 2.5$ 
$\mathrm{mmHg}(\mathrm{P}<0.05)$ and was accompanied by a small increase in HR $(+5 \pm 1 \mathrm{bpm})$. In these animals, the electrical stimulation caused a brief tachypnea $(+38 \pm 10 \%)$, and the RNA was increased by $+63 \pm 22 \%$. Figure 5 depicts a typical tracing from an animal, showing these effects.

\section{Cardiovascular and respiratory effects of L-Glu microinjected into the MRN}

The baseline MBP of anesthetized rats was $81.0 \pm 1.6 \mathrm{mmHg}$ and $\mathrm{HR}$ was $369 \pm 7.5 \mathrm{bpm}$. Microinjections of L-Glu (0.18 M, $50 \mathrm{nl})$ into the $\mathrm{MRN}$ ( $\mathrm{N}=36$ animals) induced pressor

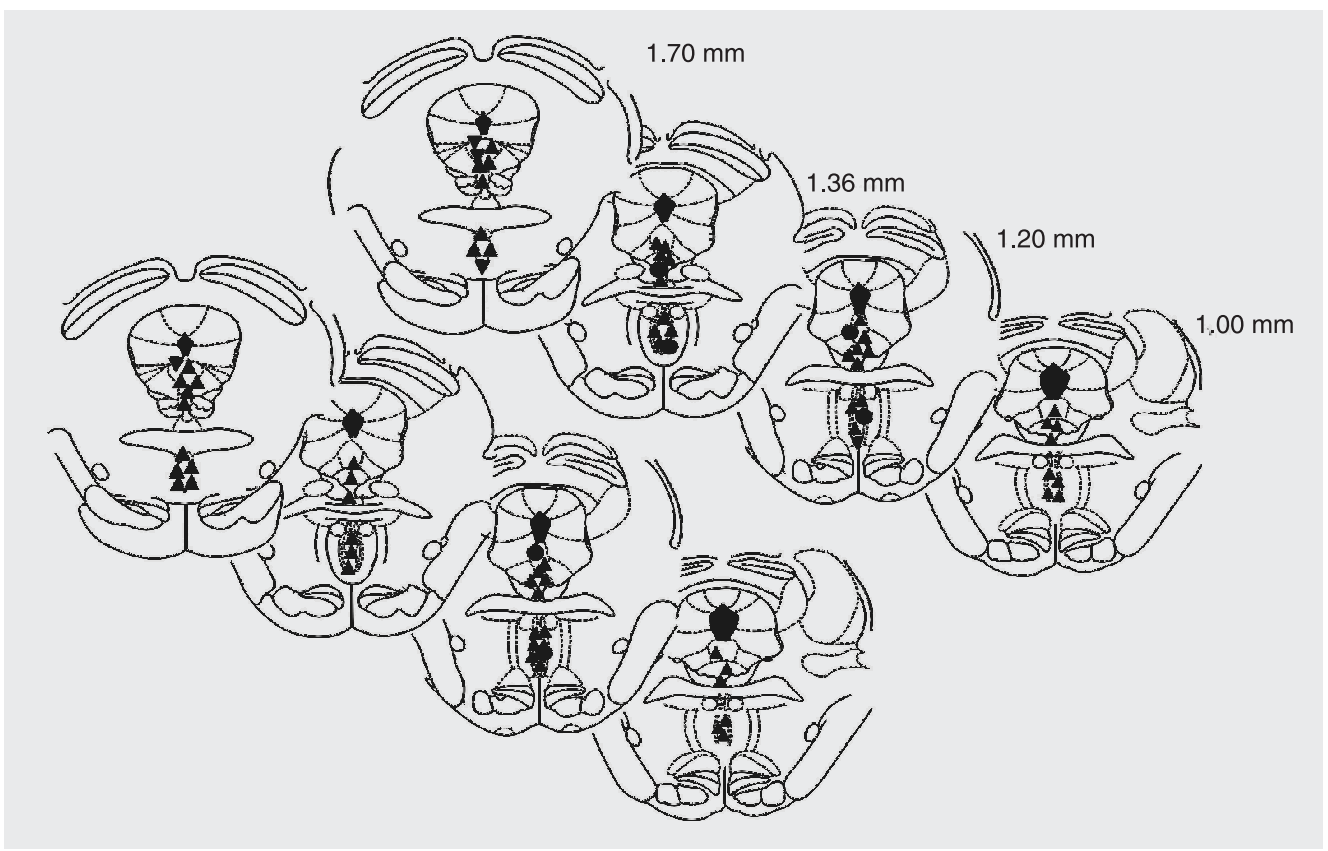

Figure 3. Schematic diagram of transverse sections of the rat brain stem showing the sites of L-glutamate microinjections. Upward triangles, downward triangles and circles denote an increase, decrease and no effect on blood pressure, respectively. Injection sites of 41 animals are shown.

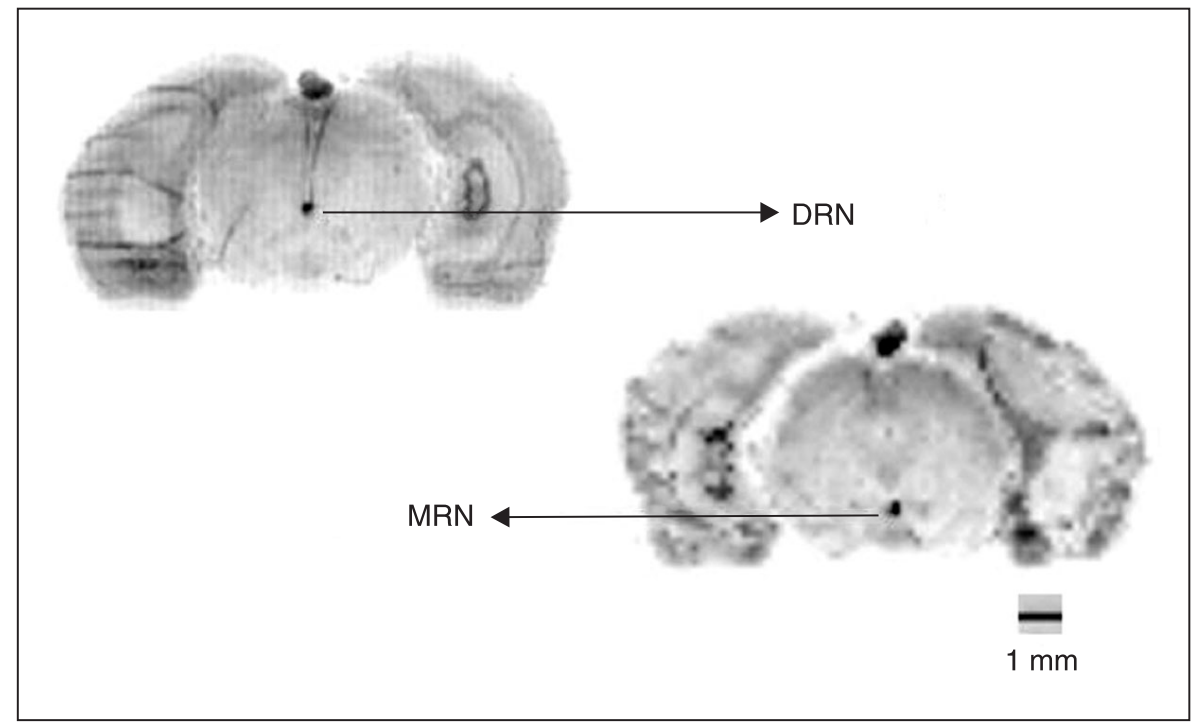

Figure 4. Transverse sections of the rat brain stem showing the sites of L-glutamate microinjections plus Pontamine Sky Blue into the DRN and MRN. DRN = dorsal raphe nucleus; MRN = median raphe nucleus. 


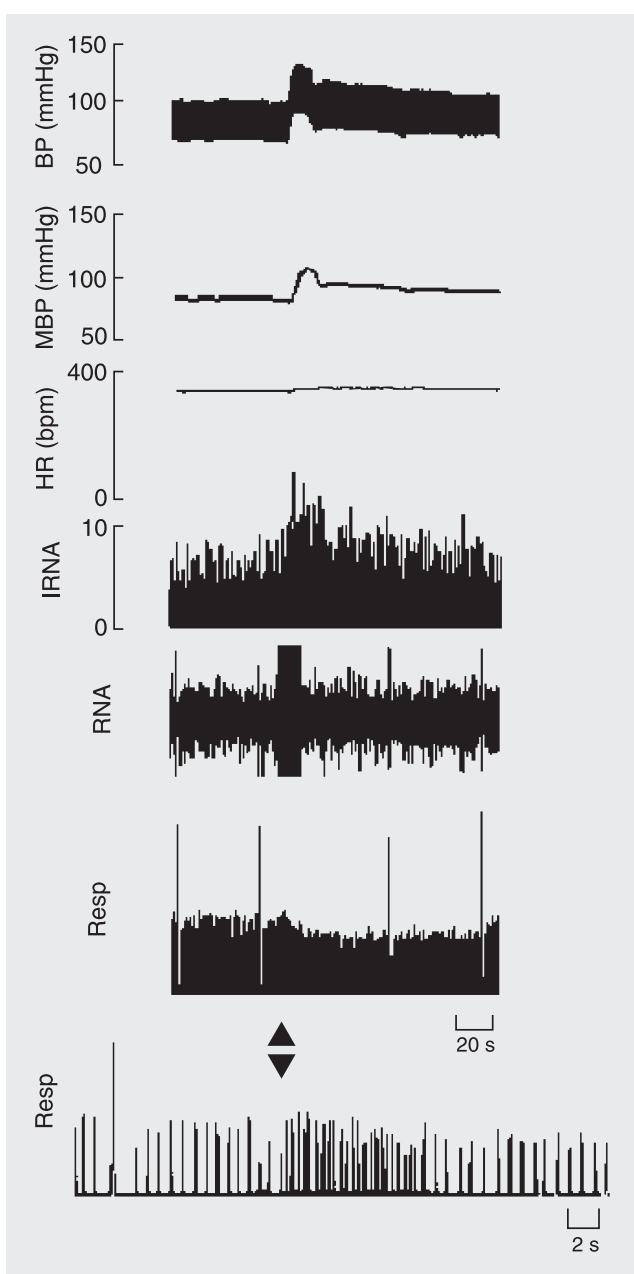

Figure 5. Electrical stimulation of the DRN causes cardiorespiratory effects qualitatively similar to those obtained by chemostimulation with L-Glu. A brief tachypnea occurred in this representative animal. Abbreviations are defined in the legend to Figure 2. The time bar corresponds to $20 \mathrm{~s}$ for all measurements except for the lower respiration tracing where it is $2 \mathrm{~s}$.

responses $(\triangle \mathrm{MBP}=+13.6 \pm 1.3 \mathrm{mmHg})$ in $88.9 \%(32 / 36)$ of the microinjection sites, hypotension in $2.8 \%(1 / 36)$ and no effect in $8.3 \%$ (3/36). Overall, the effect on BP was hypertension, without significant changes in HR (Figure 1). The pressor responses were accompanied by increases in RNA and respiratory rate of variable magnitude. A typical tracing showing these effects is shown in Figure 6. The overall changes in RNA and
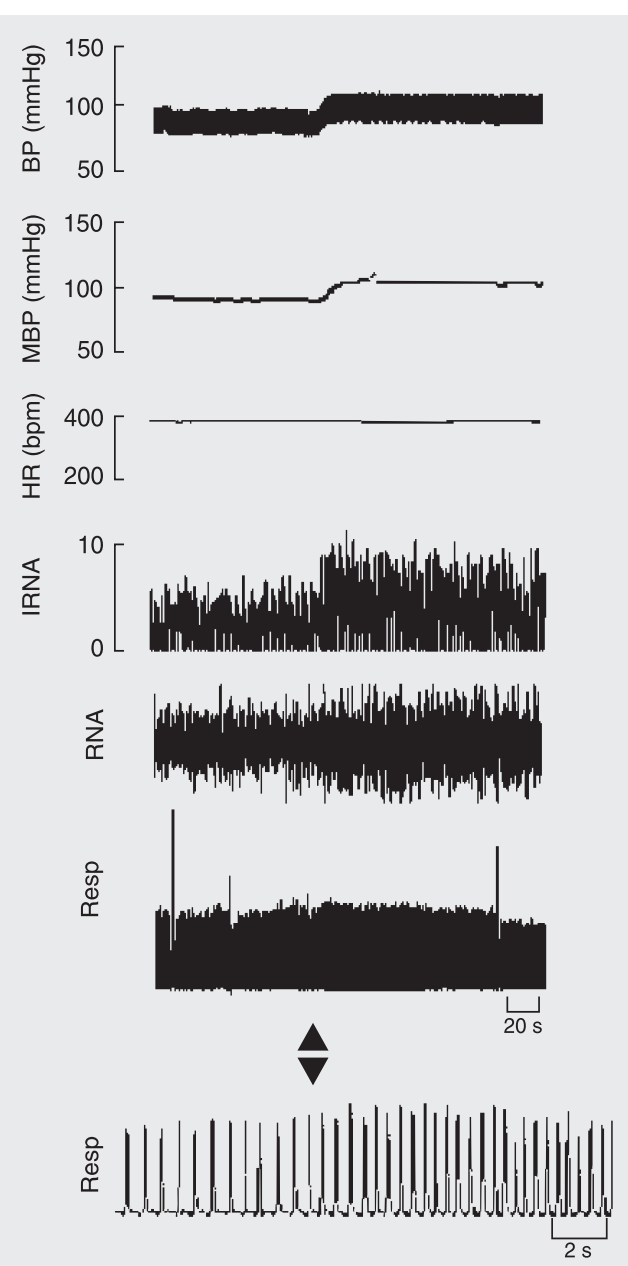

Figure 6. Typical tracing showing that L-Glu $(0.18 \mathrm{M} /$ $50 \mathrm{nl})$ microinjected into the MRN (1.2 mm AP; -8.5 $\mathrm{mm} \mathrm{V} ; 0 \mathrm{~mm} \mathrm{~L}$ ) increases blood pressure (BP), mean blood pressure (MBP), renal nerve activity (RNA), and integrated RNA (IRNA), while the effects on respiratory parameters (Resp) and heart rate (HR) are negligible. The time bar corresponds to $20 \mathrm{~s}$ for all measurements except for the lower respiration tracing where it is $2 \mathrm{~s}$.

respiratory rate caused by L-Glu were $+40 \pm$ 10 and $+29 \pm 7 \%$, respectively $(\mathrm{P}<0.05)$.

The pressor sites within the MRN were dorsoventrally distributed along the midline, without preference for caudal or rostral localization. Figure 3 shows the localization of the microinjection sites in both raphe nuclei. A typical injection site into the MRN is shown in the histological plate in Figure 4.

Microinjections made outside the MRN 
( $\mathrm{N}=13$ animals) usually did not change the cardiovascular parameters. Chemical stimulation within sites lateral to the MRN induced pressor responses $(\mathrm{MBP}=82.2 \pm 1.8$ to $95.4 \pm 2.0 \mathrm{mmHg} ; \mathrm{N}=4$ ) accompanied by a decrease in respiratory volume. In two animals a biphasic response occurred (a decrease followed by an increase in BP and $\mathrm{HR} ; \Delta \mathrm{MBP}=-9$ to $+13 \mathrm{mmHg} ; \Delta \mathrm{HR}-5$ to +9 bpm, $\mathrm{N}=2$ ), while a reduction in $\mathrm{MBP}$ was observed in two other rats $(\mathrm{MBP}=85 \pm 3.7$ to $75.3 \pm 3.2 \mathrm{mmHg}$ ). In five other animals no change in the cardiovascular parameters was induced by the stimulation (MBP $=82 \pm$ $1.4 \mathrm{mmHg}$; HR $=303 \pm 3.3 \mathrm{bpm})$. On the other hand, when the microinjection site was close to or inside the adjacent periaqueductal gray matter, pressor responses accompanied by an increase in HR were observed (data not shown).

\section{Cardiovascular and respiratory effects of electrical stimulation of the MRN}

For this group ( $\mathrm{N}=6$ animals), the baseline MBP of anesthetized rats was $87.5 \pm 2.5$ $\mathrm{mmHg}$ and the HR was $306 \pm 4.0 \mathrm{bpm}$. Electrical stimulation (as described) of sites within the MRN caused cardiorespiratory effects qualitatively similar to those obtained by chemostimulation with L-Glu. The pressor responses had a magnitude of $+28.3 \pm$ $2.5 \mathrm{mmHg}$ and were accompanied by a small increase in HR $(+6 \pm 1.5 \mathrm{bpm})$. In these animals, the electrical stimulation caused a brief tachypnea ( $\Delta$ respiratory rate $=+33 \pm$ $8 \%)$ and RNA was increased by $+57 \pm 18 \%$. Figure 7 depicts a typical tracing for an animal, showing these effects.

\section{Discussion}

A large body of evidence indicates that the DRN and MRN are the origin of almost all 5-HT terminals innervating the forebrain $(1,2)$. Projections from these nuclei are present in various regions of the hypothalamus

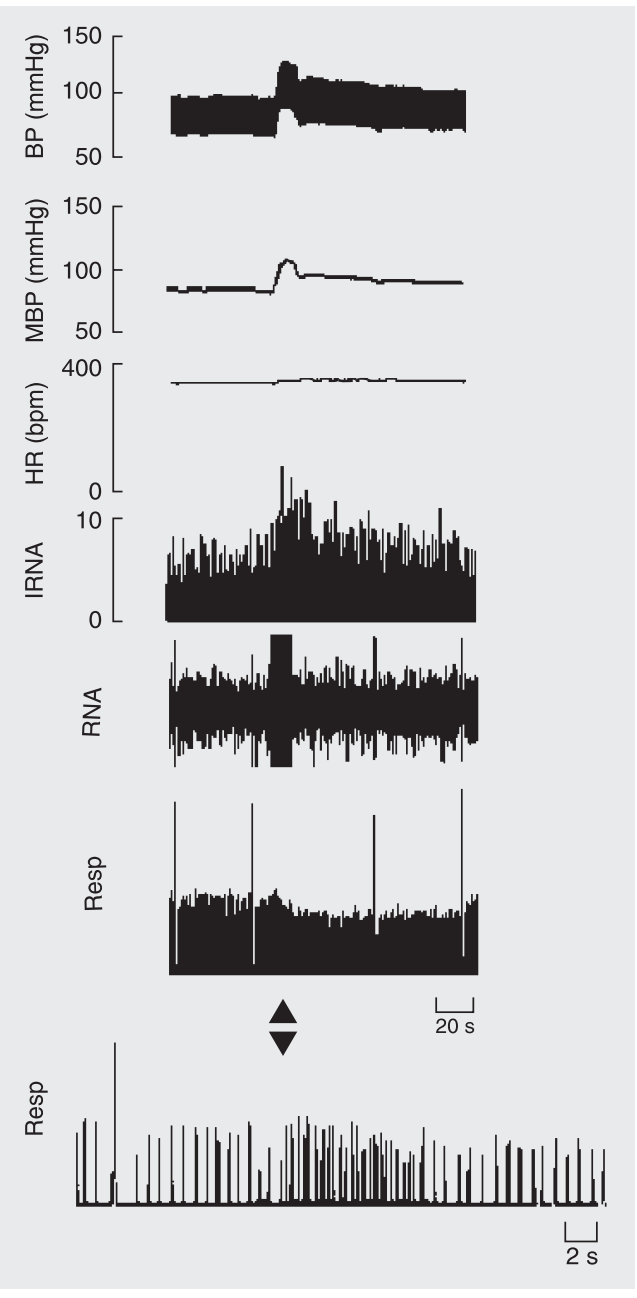

Figure 7. Electrical stimulation of the MRN causes cardiorespiratory effects qualitatively similar to those obtained by chemostimulation with L-Glu. A brief tachypnea occurred in this representative animal. Abbreviations are defined in the legend to Figure 2. The time bar corresponds to $20 \mathrm{~s}$ for all measurements except for the lower respiration tracing where it is $2 \mathrm{~s}$. and limbic system which are involved in cardiovascular regulation. The anatomical and biochemical findings raise the possibility that serotonergic projections from the DRN to the RVLM play a role in modulating cardiovascular function (26). However, the raphe nuclei also have non-serotonergic neurons which can also be excited by L-Glu microinjection.

Studies using mostly extensive electrical stimulation have suggested the participation of these areas in cardiovascular control (1719,24). These studies showed that electrical stimulation of the DRN and MRN induces mainly pressor responses in the rat, and that these responses are mediated by 5-HT. However, the studies using excitatory amino acid 
microinjections were limited and did not precisely map the DRN and MRN regarding cardiovascular, respiratory and sympathetic nerve activity responses. As stated before, the technique of electrical stimulation is not selective because it may stimulate fibers of passage as well as cell bodies.

The present study used excitatory amino acid microinjections that have an excitatory effect only on neuronal perikaria, therefore yielding reliable and precise results. A single microinjection was made in each nucleus (DRN and MRN) of each animal so as to avoid an excessive concentration of excitatory amino acids that could induce cytotoxicity. Our goal was to microinject $70 \mathrm{nl}$ into each stimulation site, but since this was not always technically possible we referred to a range of volumes. Regarding variation, we observed no change in the direction of the response but only in its magnitude, i.e., no pressor response was inverted to a depressor one due to volume or dose variations. Regarding the L-Glu dose, in previous studies (e.g., Ref. 30) some investigators employed the same or similar doses in the raphe and other nuclei with adequate results.

The localization of the pressor sites within the DRN and MRN in the present study was similar to that of sites previously mapped by electrical stimulation experiments in rats. In addition, Piper and Goadsby (19) demonstrated in the cat that 5-HT depletion with $p$ chlorophenylalanine significantly reduces the pressor response induced by DRN stimula- tion. It has been shown in cats that 5-HT microinjected into the DRN elicits hypertension that is blocked by methysergide (31), a nonselective 5-HT receptor antagonist. It has also been shown that microinjection of $5-\mathrm{HT}_{1 \mathrm{~A}}$ receptor agonists into the DRN induces a fall in BP due to the inhibition of 5HT neurons (32). Taken together, these lines of evidence indicate the participation of 5HT neurons in mediating such responses.

In our study the sites evoking pressor responses and sympathoexcitation were localized within the boundaries of the two raphe nuclei, while stimulation sites outside or DRN or MRN provoked no response or a diverse pattern of responses. Despite the paucity of data concerning the role of the DRN/MRN in respiratory control, our results demonstrate an excitatory effect of these nuclei on respiratory rate. To the best of our knowledge, there are no data describing the pathways involved in this response, although there is indirect evidence suggesting the participation of the DRN in respiratory function in the rat (33) and cat (34).

In conclusion, our results show that the stimulation of the DRN and MRN in the rat induces mainly pressor and sympathoexcitatory responses. In addition, they also indicate that DRN and MRN neurons are involved in cardiorespiratory regulation and that their projections to forebrain structures and descending projections to the spinal cord (26) participate in blood pressure control.

\section{References}

1. Dahlstrom A \& Fuxe K (1964). Evidence for the existence of monoamine-containing neurons in the central nervous system - I. Demonstration of monoamines in cell bodies of brainstem neurons. Acta Physiologica Scandinavica, 62 (Suppl 232): 1-55.

2. Moore RY, Halaris AE \& Jones BE (1978). Serotonin neurons of the midbrain raphe: ascending projections. Journal of Comparative Neurology, 180: 417-438.

3. Bacon SJ, Zagon A \& Smith AD (1990). Electron microscopic evidence of a monosynaptic pathway between cells in the caudal raphe nuclei and sympathetic preganglionic neurons in the rat spinal cord. Brain Research, 79: 589-602.

4. Chalmers J \& Pilowsky P (1991). Brainstem and bulbospinal neurotransmitter systems in the control of blood pressure. Journal of Hypertension, 9: 675-694.

5. Helke CJ, Sayson SC, Keeler JR et al. (1986). Thyrotropin-releasing hormone-immunoreactive neurons project from the ventral medulla to the intermediolateral cell column: partial coexistence with serotonin. Brain Research, 381: 1-7. 
6. Jones SL \& Light AR (1992). Serotoninergic medullary raphe spinal projection to the lumbar spinal cord in the rat: retrograde immunohistochemical study. Journal of Comparative Neurology, 322: 599-610.

7. Loewy AD (1981). Raphe pallidus and raphe obscurus projections to the intermediolateral cell column in the rat. Brain Research, 222: 129-133.

8. Morrison SF (1993). Raphe pallidus excites a unique class of sympathetic preganglionic neurons. American Journal of Physiology, 265: 82-89.

9. Azmitia EC \& Segal M (1978). An autoradiographic analysis of the differential ascending projections of the dorsal and median raphe nuclei in the rat. Journal of Comparative Neurology, 179: 641-667.

10. Steinbusch HW, van der Kooy D, Verhofstad AA et al. (1980). Serotonergic and non-serotonergic projections from the nucleus raphe dorsalis to the caudate-putamen complex in the rat, studied by a combined immunofluorescence and fluorescent retrograde axonal labeling technique. Neuroscience Letters, 19: 137-142.

11. O'Hearn E \& Molliver ME (1984). Organization of raphe-cortical projections in rat: a quantitative retrograde study. Brain Research Bulletin, 13: 709-726.

12. Vertes RP \& Martin GF (1988). Autoradiographic analysis of ascending projections from the pontine and mesencephalic reticular formation and the median raphe nucleus in the rat. Journal of Comparative Neurology, 275: 511-541.

13. Vertes RP (1991). A PHA-L analysis of ascending projections of the dorsal raphe nucleus in the rat. Journal of Comparative Neurology, 313: 643-668.

14. Charara A \& Parent A (1994). Brainstem dopaminergic, cholinergic and serotonergic afferents to the pallidum in the squirrel monkey. Brain Research, 640: 155-170.

15. Vertes RP \& Kocsis B (1994). Projections of the dorsal raphe nucleus to the brainstem. Journal of Comparative Neurology, 340: 11-26.

16. Vertes RP, Fortin WJ \& Crane AM (1999). Projections of the median raphe nucleus in the rat. Journal of Comparative Neurology, 407: 555-582.

17. Smits JFM, Van Essen H \& Struker-Boudier AAJ (1978). Serotoninmediated cardiovascular responses to electrical stimulation of the raphe nuclei in the rat. Life Sciences, 23: 173-178.

18. Kuhn DM, Wolf WA \& Lovenberg W (1980). Pressor effects of electrical stimulation of the dorsal and median raphe nuclei in anesthetized rats. Journal of Pharmacology and Experimental Therapeutics, 214: 403-409.

19. Piper RD \& Goadsby PJ (1985). Pressor response to electrical and chemical stimulation of nucleus raphe dorsalis in the cat. Stroke, 16: 307-312

20. Graeff FG, Guimarães FS, De Andrade TGCS et al. (1996). Role of 5-HT in stress, anxiety, and depression. Pharmacology, Biochemistry, and Behavior, 54: 129-141.
21. Kalen P, Skagerberg G \& Lindvall O (1988). Projection from the tegmental area and mesencephalic raphe to the dorsal raphe nucleus in the rat. Evidence for a minor dopaminergic component. Brain Research, 73: 69-77.

22. Marcinkiewiez M, Morcos R \& Chretien M (1989). CNS connections with the median raphe nucleus: retrograde tracing with WGAapoHRP-Gold complex in the rat. Journal of Comparative Neurology, 289: 11-35.

23. Tischler RC \& Morin LP (2003). Reciprocal serotonergic connections between the hamster median and dorsal nuclei. Brain $R e$ search, 981: 126-132.

24. Robinson SE, Rice MA \& Davidson W (1986). A GABA cardiovascular mechanism in the dorsal raphe of the rat. Neuropharmacology, 25: 611-615.

25. Reis DJ, Morrison SF \& Ruggiero DA (1988). The C1 area of the brainstem in tonic and reflex control of blood pressure. State of the art lecture. Hypertension, 11: |-8-|-13.

26. Underwood MD, Arango V, Bakalian MJ et al. (1999). Dorsal raphe nucleus serotonergic neurons innervate the rostral ventrolateral medulla in rat. Brain Research, 824: 45-55.

27. Lin L-S \& Lin M-T (1996). Hypothalamic serotonin release and raised blood pressure after raphe nuclei stimulation in rats. Brain Research Bulletin, 39: 305-309.

28. Pires JGP, Alvarenga RM \& Futuro-Neto HA (2001). A functional study of the role of dorsal and median raphe nuclei in cardiorespiratory regulation. Society for Neuroscience Abstracts, 27: 836.13 (Abstract).

29. Paxinos G \& Watson C (1996). The Rat Brain in Stereotaxic Coordinates. 2nd edn. Academic Press, San Diego, CA, USA.

30. Silva NF, Pires JGP, Campos RR et al. (2001). Cardiovascular and respiratory responses to microinjection of L-glutamate into the caudal pressor area in conscious and anesthetized rats. Brazilian Journal of Medical and Biological Research, 34: 1603-1606.

31. Saxena AK, Saksena AK, Agnihotri MS et al. (1985). Cardiovascular responses elicited by microinjection of monoamine into mesencephalic nucleus dorsalis raphe in cats. Naunyn Schmiedebergs Archives of Pharmacology, 392: 141-145.

32. Connor HE \& Higgins GA (1990). Cardiovascular effects of $5-H_{1} T_{1 A}$ receptor agonists injected into the dorsal raphe nucleus of conscious rats. European Journal of Pharmacology, 182: 63-72.

33. Martin-Body RL \& Grundy HR (1985). Effects of neurotoxin-induced brainstem lesions on the respiratory responses of conscious rats. Clinical and Experimental Pharmacology and Physiology, 12: 427437.

34. Veasey SC, Fornal CA, Metzler CW et al. (1997). Single-unit responses of serotonergic dorsal raphe neurons to specific motor challenges in freely moving cats. Neuroscience, 79: 161-169. 